\title{
Research on High Frequency PI Section Control of Electrochemical DC Power Supply
}

\author{
FU Guang-Jie ${ }^{1, a}$, LIN Yu-qing ${ }^{2, b}$ \\ ${ }^{1,2}$ Department of Electrical Engineering and Information, Northeast Petroleum University, \\ Heilongjiang Daqing, 163318, China \\ aemail:fgjmhw@163.com, bemail:blair5107@sina.com
}

Keywords: Full-bridge converter circuit; High-frequency PWM; Section PI control

\begin{abstract}
In the chemical industry, a large pressure range, relatively stable voltage output DC power supply is often required. This paper mainly studied on the control method of DC conversion circuit. The full-bridge configuration electromagnetic isolation has advantages in efficiency and pressure range. The high-frequency PWM control mode was used in control circuit. The entire system using voltage feedback loop PI control method of segmentation and the pressure range is divided into multiple parts separately controlled. And MATLAB simulation results suggest that this control method can reduce the amount of ripple output voltage waveform.
\end{abstract}

\section{Introduction}

DC power supply is widely used in eclectrolysis and plating process. The changes of solution concentration lead to constant changes of the solution conductivity. In this case, the stability of voltage, constant current and large pressure regulating range are indispensable to DC supply [1]. This paper will use the full bridge isolated electromagnetic DC-DC converter circuit and high frequency Bi - Directional PWM control strategy to further reduce the pulse of output waveform. PI Section Control method is adopted in the process of voltage feedback closed loop control, to ensure the stability of output voltage so that system stability can be improved.

\section{The electromagnetic isolated of full bridge converter circuit}

In order to overcome the shortcomings of traditional buck chopper circuit, a full bridge DC convert circuit is designed. The circuit structure is shown as figure 1.

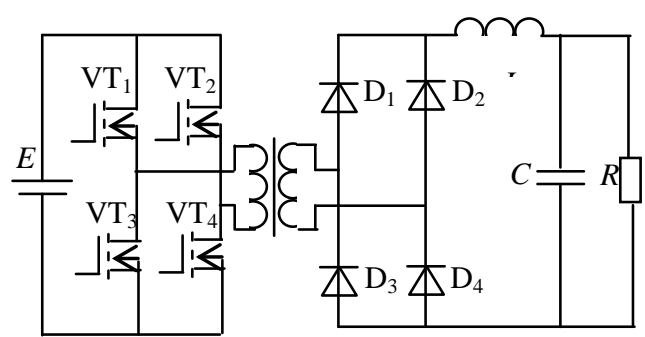

Fig.1. Electrical isolated full bridge circuit

The full bridge circuit transformer which is bidirectional excitation and has high efficiency, using four switches can achieve greater power. Meanwhile the structure of the circuit is symmetrical and doesn't produce magnetic bias. This circuit has the following features: it has larger pressure range, stable output, and relatively high efficiency [2]. Therefore, the DC power supply, in the process of electrochemical reaction, requires large voltage regulation range and stable voltage output.

\section{High frequency PWM control strategy}

To change the output voltage, we can modulate the pulse width and duty cycle. Applying the PWM control technology in the DC converter can realize the purpose of regulating voltage better. 
With the increase of carrier frequency, isolation transformer will have a high efficiency. The pulse number of output current at unit time $t$ is:

$$
n=2 \times \frac{t}{T}
$$

In order to achieve the stability of the output, it is better to have more pulses during the time $t$. And in each cycle $T$ the output energy $E$ is:

$$
E=D U_{i} \int_{0}^{T} i_{i} d t=U_{0} \int_{0}^{T} i_{0} d t
$$

In the process of changing the duty ratio $\mathrm{D}$, the smaller the pulsing current, the more ideal of the voltage regulating is.

\section{PI Section Control strategy}

The traditional PI control, which not only has a high control speed, but is also easy to be realized, is suitable for high frequency DC converter circuit [3]. The control can be expressed as:

$$
u=K_{p} e+K_{i} \int_{0}^{t} e d t=U_{0} \int_{0}^{T} i_{0} d t
$$

PI control can acquire good effect in linear systems, and are even applied in non-linear control systems which is coped as linear system by the appropriate transform. Because the electromagnetic isolation bridge DC convert circuit is not strictly linear systems [4], we adopt the section PI control which means that the voltage regulating range is divided into several sections. Schematic diagram as shown in figure 2 below.

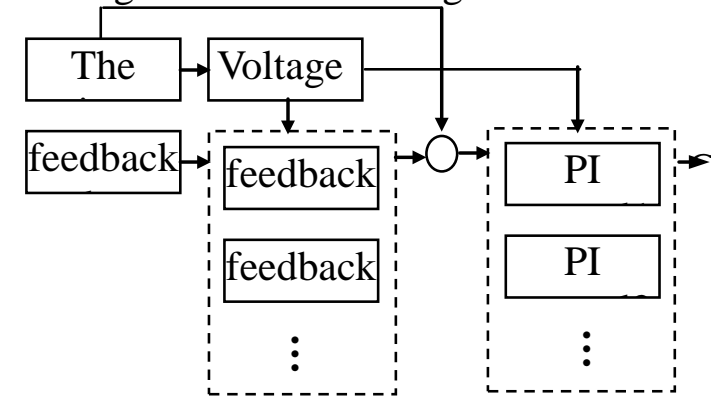

Fig.2. The section control principle diagram

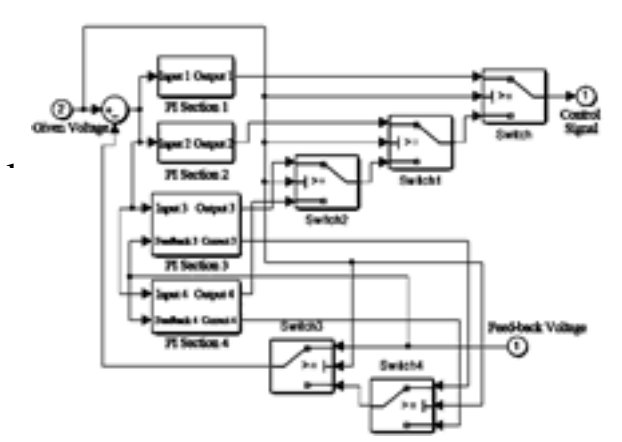

Fig.3.the model of Section PI control

According to the given voltage, the range of regulating voltage $[a, b]$ can be divided into several interval, such as:[a, $\left.a_{1}\right],\left[a_{1}, a_{2}\right] \cdots\left[a_{n}, b\right]$.First of all, an adjustment is made according to the error feedback signal in each interval. Then compare the given voltage and the feedback voltage to get the difference. Finally, to get the final control signal, in different sections diverse proportional and integral coefficients are adjusted.

\section{Simulation and Analysis}

The simulation model of voltage regulating system can be realized easily through MATLAB. The model of Section PI control as shown in figure 3.

The voltage of DC power supply is $110 \mathrm{~V}$ and the frequency of PWM triangular carrier wave is $500 \mathrm{~Hz}$. Adjusting the isolation transformer turns ratio so that the range of the output voltage is $10 \mathrm{~V}$ to $86 \mathrm{~V}$. The section $\mathrm{Pi}$ control according to the simulation results are divided into four sections:[10,15],[15,30],[30,70] and [70,86]. At 3 seconds the output load resistor is paralleled a 10 $\mathrm{k} \Omega$ resistor as a disturbance and set a voltage regulating process at 5 seconds. The allowed range of voltage error is less than $2 \%$.In the section PI control, the given voltage changes from $86 \mathrm{~V}$ to $76 \mathrm{~V}$, the output voltage waveform of the circuit as shown in Figure 4. And Figure 5 shows the result of the given voltage changed from $15 \mathrm{~V}$ to $10 \mathrm{~V}$. 


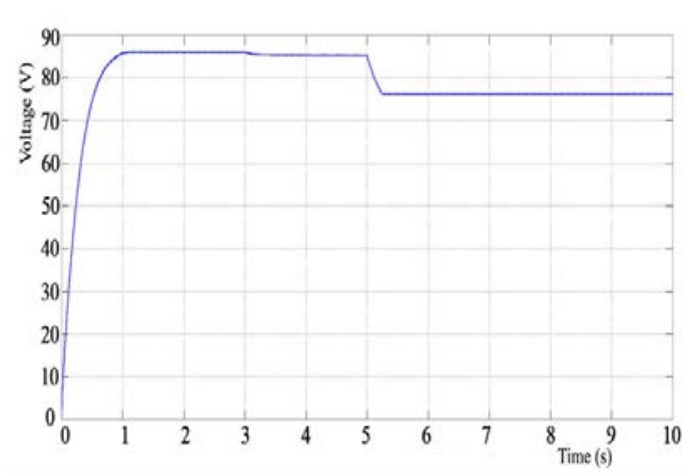

Fig.4.the output voltage waveform: given voltage is from $86 \mathrm{~V}$ to $76 \mathrm{~V}$

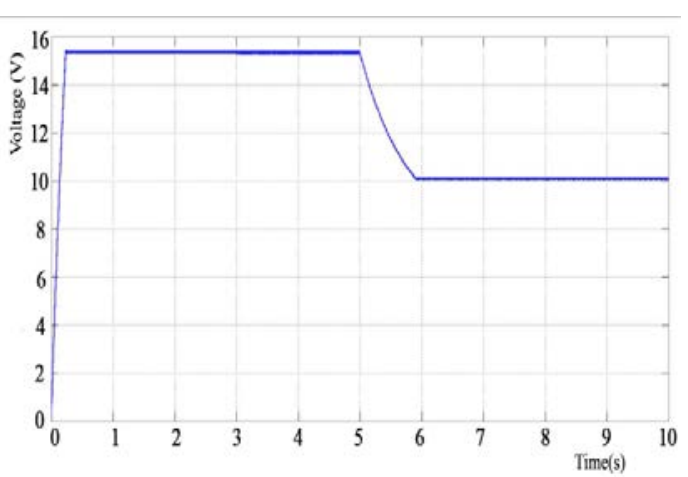

Fig.5.the output voltage waveform: given voltage is from $15 \mathrm{~V}$ to $10 \mathrm{~V}$

The simulation results suggest that the electromagnetic isolation bridge DC convert circuit with section PI control can regulate the voltage from $86 \mathrm{~V}$ to $10 \mathrm{~V}$. The waveform of the output voltage is very stable, almost no pulse. In the process of the voltage regulating, the changing of the voltage is very smooth and the respond speed is fast greatly. Figure 6 shows the result of the given voltage changing from $30 \mathrm{~V}$ to $25 \mathrm{~V}$ with traditional PI control. While figure 7 illustrates the waveform of given voltage changing from $86 \mathrm{~V}$ to $76 \mathrm{~V}$ when the carrier frequency is down to $50 \mathrm{~Hz}$.

As is suggested in Figure 6, in the absence of section PI control, the output voltage ripple is relatively small. Therefore, without section $\mathrm{Pi}$ control the range of regulating voltage will be reduced to $86 \mathrm{~V}$ to $30 \mathrm{~V}$.While Figure 7 shows that the amount of output voltage ripple will significantly increase and the overshoot will increase at the same time when the frequency of carrier signal is reduced. So the high frequency PWM control plays a key role in the system output voltage stability.

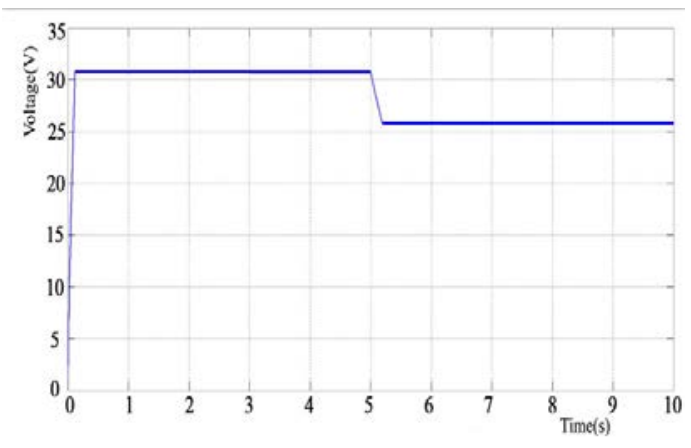

Fig.6.the output voltage of the traditional PI control

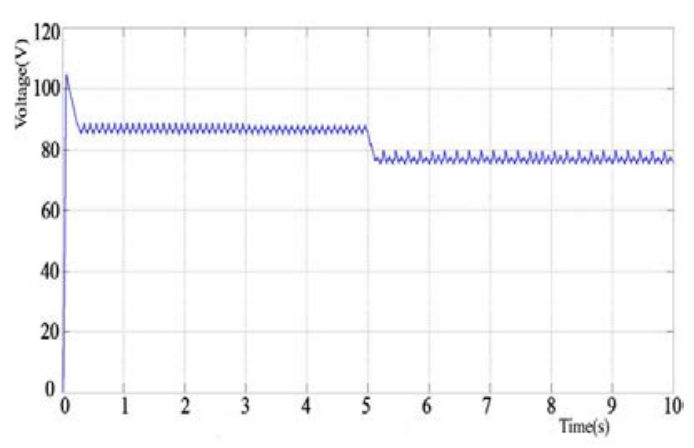

Fig.7.the output voltage when the Carrier frequency down to $50 \mathrm{~Hz}$

\section{Conclusion}

This paper has mainly discussed the electrochemical DC power supply circuit and got the conclusion that electromagnetic isolated full bridge converter circuit is most suitable for electrochemical DC voltage regulating circuit by analyzing the DC converter circuit. As for the control circuit, adopting the high-frequency bipolar PWM signal and higher speed section PI control tragedy to improve output voltage regulating range and reduce the fluctuation. Finally, the experimental results shows show the feasibility and validity of the proposed section Pi control modulation scheme.

\section{References}

[1] Nakaoka, M, Saha, B, Sugimura, H, Sang Pil Mun, Hiraki, E, Omori, H. Direct High Frequency Soft Switching Inverter Type AC-DC Power Converter with Boost Function for Consumer Magnetron Drive, Industrial Electronics Society, 2007. IECON 2007. 33rd Annual Conference of The IEEE, Page(s): 1336-1341 
[2] P. Shamsi and B. Fahimi "Design and development of very high frequency resonant DC-DC boost converters", IEEE Trans. Power Electron., vol. 27, no. 8, pp.3725 -3733 2012.

[3] Nymand M, Andersen M A E. High-efficiency isolated boost DC - DC converter for high-power low-voltage fuel-cell applications [J]. Industrial Electronics, IEEE Transactions on, 2010, 57(2): 505-514.

[4] Choe, H. J., et al. (2014). "Passive Snubber for Reducing Switching-Power Losses of an IGBT in a DC-DC Boost Converter." IEEE Transactions on Power Electronics 29(12): 6332-6341.

[5] Y.-J. Kim and H. Dohmeki, "Driving method of stationary discontinuous-armature PMLSM by open-loop control for stable-deceleration driving," IET Electr. Power Appl., vol. 1, no. 2, pp. 248-254, March 2007. 